\title{
Guardian angels and teachers from hell: using metaphor as a measure of schools' experiences and expectations of General National Vocational Qualifications.
}

\begin{abstract}
.
In this paper I examine some claims about the nature of metaphor, its possible significance in illuminating cultural, institutional and personal constructs, and some ways in which this has been applied in educational research. To illustrate the application of metaphor analysis, the paper describes an examination of the figurative language used by teachers and headteachers in six English secondary schools when speaking about their new vocational curriculum and its students. Transcripts of interviews were scrutinized for metaphorical and other figurative modes of expression, and instances were identified of recurring patterns and themes. This paper argues that the metaphorical language employed within each of the schools reflects a lower level of esteem for the vocational qualification and the pupils taking it than that which is overtly expressed, and suggests that the negative metaphors employed by the headteacher may be instrumental in determining the status of such qualifications within the school.
\end{abstract}

Author's biographical note

Susan Wallace is a senior lecturer in Education at The Nottingham Trent University. Her research interests are in post-sixteen education, with special emphasis on the status of general vocational provision. As well as studies of this provision in schools, her current research explores student motivation in colleges of further education.

Correspondence to Susan Wallace, Department of Secondary and Tertiary Education, The Nottingham Trent University, Clifton, Nottingham NG11 8NS. email: sue.wallace@ntu.ac.uk 


\section{About metaphor}

A mastery of metaphor, according to Aristotle, is a sign of genius, an indication of the ability to see the connectedness of things. In this sense - the making of connections - metaphor can be instrumental in creating new ways of seeing. As Way (1994: 8) points out, when our current repertoire of concepts proves inadequate, metaphor allows us to reorganise those concepts in new ways "in order to explore different and startling perspectives". But metaphor can be viewed not only as a function of creative thought, capable of jolting us into new ways of thinking, "a central feature of the production and reproduction of meaning" (Taylor, 1984: 20), but also as an indication of how we construe the world. Lakoff and Johnson (1980: 3) argue that our conceptual system is, in its very nature, metaphorical and that, although we have little day-to-day awareness of that system, we can look to language, to the metaphors embedded there, as evidence of what that conceptual system is like. In both these senses - as creative thought or as a key to our personal and collective constructs - metaphor is viewed as more than a poetic flourish or a trick of language, but rather as something which "resides in thought, not just in words" (Lakoff and Turner, 1989: 2). In examining the metaphors used in discourse about schools' vocational curriculum, therefore, I am taking such figures of speech to be one indicator of how this provision is viewed, individual or institutional attitudes towards it, and the value attached to it; and I am entertaining the possibility that the metaphors may indicate an attitude inconsistent with what is intentionally expressed.

Put at its simplest, a metaphor functions to link two usually unassociated ideas or objects in order to highlight a similarity or similarities between them. For a more detailed analysis of how this process works it is useful to refer to Black (1962 and 1979) and what he terms the "interaction view" of metaphor. Briefly, he suggests that in any metaphorical statement there are two subjects, the "primary" and the "secondary" Thus in the metaphor, a school is a garden, the secondary subject is garden and indicates the existence of what Black calls "the implicative complex" (Black, 1979: 28) - a system of relationships. This complex of properties or ideas is projected on to the primary subject, in our example, school, thereby inviting the reader or hearer to select particular features of the implicative 
complex and fit them to the primary subject. This process may also produce reciprocal, if minor changes in the way the secondary subject is perceived. A metaphorical statement, therefore, is dependent for its effectiveness upon an active creative response from the hearer or listener. Herein lies one of the difficulties of using metaphor as a diagnostic device, as an outward and unambiguous indicator of underlying constructs and attitudes. To illustrate what I mean by this let me take an example from a work of fiction written only sixty or so years ago:

"My old passion for queer company has stood me in good stead, and by voluptuous curves l've been trying to get in on their flanks."

(Buchan, 1936: 213)

The metaphors here are opaque, or at best ambiguous. The character is, in fact, describing his success at infiltrating a gang of villains. Our problem is that his images and allusions derive not only from a time but also a social stratum with which most of us are now unfamiliar. Inevitably our social and cultural backgrounds have a bearing on how we interpret texts, be they novels or interview transcripts; but Eco (1990) would argue that there are usually properties of a text which do set some limits on the range of interpretations which it is legitimate to make. He gives the example of two metaphors:

"Achilles is a lion"

and

"Achilles is a duck"

(Eco, 1990: 63)

From the first we understand that Achilles is fierce or brave or both of these; and most would agree that this metaphor works. From the second we are to understand, possibly, that Achilles has two legs; or perhaps that he can swim well. Whatever the case, this metaphor fails to work because it does not engage with our shared understanding about Achilles. Similarly, to go back to Buchan, when another of his characters uses the simile, "healthy as a trout" (Buchan, 1936: 119) we may be puzzled if we have only ever seen 
trout lying dead under clingwrap or on a plate. Buchan, however, probably expected his readers to view trout, as he did, from the perspective of a fisherman: as lively, rapid swimmers. To most of us today the connectedness between good health and a trout is certainly less than obvious.

This danger of cognitive dissonance in the field of metaphor dominates the plot of a Startrek episode. In this, the crew of the Enterprise encounter an alien race, the Tarmarians, who are officially described as "incomprehensible." After a series of frustrating attempts at communication, Captain Picard suddenly realises what is going on and exclaims, "That's how you communicate, isn't it? By citing example! By metaphor!" But without a knowledge of their history and mythology the Tarmarians' culturally specific allusions remain incomprehensible to the humans. As another character points out, "The situation is analogous to understanding the grammar of a language, but not the vocabulary." The ship's counsellor explains that:

"Imagery is everything to the Tarmarians. It embodies their emotional state, their very thought processes. It's how they communicate and it's how they think."

If we substitute "humans" for "Tarmarians" we see that, far from boldly going where no-one has gone before, the counsellor is simply paraphrasing Lakoff and Johnson (1980).

Because the metaphors embedded in our language may be seen in this way, as a reflection of our shared conceptual system, it can be argued that metaphor is located within langue (Cohen and Margalit, 1972). If this were invariably the case, it would be difficult to justify the drawing of conclusions about any individual's attitude or value system by reference to the metaphors he or she employs. A pragmatic view would, however, locate metaphor within parole, where the words which constitute an individual act of speech may be chosen to evoke a particular imaginative intellectual response. A clear example of this would be a poet's use of metaphor. Black's (1979) interaction view stresses metaphor's role in conveying beliefs rather than meanings; and a psychoanalytical approach would take this further, claiming that images may be generated independently of the conscious 
mind's control, and that these images may be used as evidence of the individual's preoccupations, values or beliefs (Samuels, 1985: 41).

In this inquiry, therefore, the transcribed interviews with teachers and headteachers were analysed in order to identify examples of "idiosyncratic" metaphors (Inbar, 1991) rather than those that are familiar and shared; metaphors as parole rather than as lange. It was decided to discount what Orwell (1962: 146) calls "dead" or "worn out" metaphors those which no longer evoke any clear idea of their origins, as when something is said to "go by the board"; rarely, today, would this evoke an image of anything toppling over the side of a ship. Taylor (1984) suggests that metaphors may be defined as "dead" when there is no longer commonly perceived to be any duality of meaning. Black (1979: 25), however, condemns the concept of dead metaphor as "trite", and argues that there are differing degrees of obscurity. He suggests a typology of metaphors which classifies them as "extinct", "dormant", and "active" - itself an intriguingly "active" volcanic metaphor - and according to which some of Orwell's dead metaphors might be deemed merely "dormant", while Taylor's would be deemed "extinct". For the purposes of this inquiry, only metaphors which retain some duality of meaning were considered to be useful indicators of attitude.

\section{The purpose of the inquiry}

This paper is based upon an investigation into the use of metaphor by teachers of the General National Vocational Qualification (GNVQ) and their headteachers, and is based upon interviews carried out in six English secondary schools. From the time of its first mention in a British government white paper (DfE 1991) the Advanced GNVQ has been described as having parity of esteem with the traditional academic route, the Advanced General Certificate of Education (A level GCE). Accordingly, in all six of these schools the declared policy was that students who had chosen the Advanced GNVQ option postsixteen were to be considered equal in status to A level students. The primary purpose of the investigation was to discover whether the metaphors used in relation to GNVQs were consistent with this policy and with current claims that the qualification has "parity of esteem" with A levels (DfE 1991). Transcripts of the interviews were analyzed in order to discover whether this policy of equality was reflected in the figurative language used to describe GNVQs and GNVQ students. The initial analysis suggested a further line of 
inquiry: whether there might be a thematic consistency in the metaphors used in relation to GNVQs within each school; and if so, whether this might derive from or reflect the views of the headteacher. In the first part of the paper I have examined some claims about the nature of metaphor, and its possible significance in illuminating cultural, institutional and personal constructs. In the following section consideration will be given to the application of metaphor in the field of educational research. The paper will then go on to summarize the evidence from the investigation and to conclude that in so far as there is a thematic consistency in metaphor use within a school, this appears to reflect the policies or attitude of the headteacher; and that the metaphors used for and about GNVQs are, in most cases, at odds with the principle of "parity". The title of the paper draws upon two metaphors used by a teacher to describe how their role was seen in relation to the GNVQ students whom they taught. Although the images appear contradictory, they express the idea that these students require help and intervention on a supernatural scale. To this extent the words chosen for the title reflect the view expressed in some form by most of the interviewees that these students are deficient or overly dependent. The full context and analysis of the metaphors quoted in the title are dealt with in more detail below in the section headed 'Teachers' use of metaphor'.

\section{Metaphors of education}

The focus upon idiosyncratic and active metaphors used in relation to a particular aspect of education is not new. One thinks, for example, of Freire's image of "banking" to describe the limited concept of education where the sole transaction is the depositing of knowledge from teacher to pupil (Freire 1972). Bowring-Carr (1993) points to how the increasingly used metaphor of teachers "delivering" the curriculum implies a lack of professional engagement, a reduction of teachers' status from initiative-taker to mere messenger. The use of the consumer metaphor, too, to describe the educational process has been defended by Hill (1995) as accurate; and praised by Spence (1995) as creating new ways of thinking about education. Goens (1996), in a paper which explores the possibility that schools may have (in a figurative sense) a "soul", suggests that it is more constructive to describe school processes not in terms of business or industry at all but through metaphors derived from theology and philosophy. The important point I would wish 
to emphasize about all these metaphors is that they not only seek to illuminate the thing described - be it school, the curriculum, or the process of education itself - but they also throw light on how we conceive of it, a concept which includes implicit value judgements. As deBotton (1997: 97) points out:

"how we describe the world must at some level reflect how we first experience it." (Original italics)

The belief that an analysis of metaphor use is a reliable way of making otherwise unvoiced assumptions explicit has informed the methodology of a number of recent pieces of educational research. Beavis and Thomas (1996), for example, take the metaphors used by members of the governing bodies of five Australian schools as indicators of those governors' expectations of the school and of what might be expected of the governing body. This is based on the argument that metaphors "express values, which in turn store expectations at a very abstract level" (Beavis \& Thomas, 1996: 104). Using this approach they found that expectations included the idea that schools would operate on a similar model to a factory or "production company" (Beavis \& Thomas, 1996: 102). The important point here is their argument that such a metaphor is not consciously chosen; that, in Freudian terms, it is an expression of unconscious attitudes and expectations. To support this, they draw upon the work of Beare, Caldwell \& Millikan (1989) who, in stressing the importance of metaphors as a reflection of the shared organisational culture of a school, point out that:

"Metaphors are rarely consciously chosen, nor is the significance of their inherent symbolism clearly understood" (Beare et al, 1989: 188);

but that:

"When an organisation is described as a machine, or as an organism, or as a system, or as a team, or as theatre, 
each metaphor carries different value orientations, different conceptions of how the organisation operates, different ideas about its purpose" (Beare et al, 1989: 31).

Elsewhere, Beare focuses upon the importance of the principal or headteacher's use of metaphor in determining the ethos and culture of a school (Beare, 1987). The work of David and Graham (1997) on organisational leadership supports this view. They analyzed the discourse of a senior manager whose intention was to extol teamwork, and found that the metaphors it contained were of individual heroic acts and competition rather than joint effort and co-operation (David \& Graham, 1997: 24). These epic metaphors, that take war and sport as their theme, suggested that there was a conflict between the unconscious values of the speaker and those values he wished consciously to express. This sends "an ambiguous message" (David \& Graham, 1997: 27) to employees about the ethos of their organisation. David and Graham refer to their research method as "hermeneutic analysis" and draw upon Lakoff and Johnson (1980) to support their methodological approach.

Another researcher to focus upon metaphor is Inbar (1991) who, inquiring into the concept of educational planning in Israeli schools, asked various groups including teachers, principals and administrators at ministerial level, to come up with metaphors of educational planning. The metaphors were then grouped and analysed. In support of his method, Inbar (1991: 24-25) argues that:

"In using the metaphorical approach it is assumed that choice of language is not accidental and represents more than the surface meaning of the concepts........ It might thus serve as a link between tacit knowledge, which is not readily accessible, and the explicit.'

The constructs that emerged included, amongst others, planning as a recipe, as a compass, as a map, as a tree and as Ariadne's thread (Inbar, 1991: 26-31). Why knowing this was helpful, however, is not made clear. 


\section{Key concepts}

To summarise this section I want to draw attention to those key ideas in these examples of research which have informed my own inquiry:

1. That an individual's use of metaphor may express unarticulated or unconsciously held values and attitudes (Beavis \&Thomas, 1996; Beare et al, 1989; Inbar, 1991).

2. That these values and attitudes may be at odds with those consciously expressed (Beare et al, 1989; David \&Graham, 1997; Beavis \& Thomas, 1996).

3. That the metaphors used by an organisational leader to describe their organisation may significantly shape organisational culture and ethos (Beare et al, 1989; Beare, 1987; David \&Graham, 1997).

My inquiry explores these ideas in relation to the metaphors used in six schools about GNVQs. In addition, it poses a further question: Is there some consistency of theme between a headteacher's metaphors and those used by their staff?

\section{Method and methodology}

Interviews with the headteachers and teachers of the six schools were based upon the following questions:

* Why had GNVQs been introduced as part of sixth-form provision?

* How would they describe the pupils they expected to recruit to GNVQs?

* What was the current situation with regard to GNVQ provision in their school?

Within the very flexible framework of these questions, the headteachers were allowed to focus upon any aspect of GNVQ provision that currently preoccupied them. In this sense they were treated as informants rather than as respondents (Powney \& Watts 1987). The interviews were tape-recorded and later transcribed, and the transcripts passed back to the interviewees for checking. Only one headteacher asked for some of what he had said to be with-held. Working with tapes and transcripts allowed for repeated checking of data. The 
tapes themselves have been retained as an evidence archive, so that metaphor patterns can be verified and possibly used as comparative data in further research with the same schools or with others.

The search for metaphors in the interview transcripts by-passed some of the difficulties often associated with qualitative analysis of interview data. For example, the identification and tagging of sentences and phrases that operated as metaphors was relatively straightforward, once a working definition of metaphor, as described in the preceding sections, had been established. When the metaphorical constructs in the transcripts had been identified and highlighted they were categorised in order to discover any emerging themes: babies, burdens, transport and so on. A category was taken to be significant if it contained two or more entries from the same transcript or from transcripts within the same school. Where themes emerged from this categorisation they were rarely exclusive. In other words, they were not the only examples of metaphor used by a particular teacher or headteacher, but represented those which were repeated or linked thematically within that discourse. Following the categorisation from individual transcripts, a search was made for "networks" (Bliss, Monk \& Ogborn, 1983) or thematic links between transcripts from the same school. This procedure did not call for complicated analytical strategies, the data falling as it did into comparatively simple and unproblematic groupings. The issue of validity, the interpretation of the metaphors as expressions of value, is more difficult. The . approach taken was similar to that of literary criticism in thedays before Critical Theory, aiming at a broad and uncontentious interpretation of whether the imagery in the metaphors suggests a positive or negative view of GNVQ and GNVQ students.

Since scrutiny of the metaphors was specifically designed to bypass what Goodson \& Walker (1989: 112) refer to as the "subject's chosen presentation of self", the possibility of the interviewee's overt response being tailored to satisfy the interviewer (Holstein \& Gubrium, 1997) is reconstellated as potentially interesting data rather than presenting epistemological difficulties. Moreover,the interviewees are not being questioned in order to elicit "facts" in what Holstein and Gubrium (1997: 117) call the "'vessel-of-answers' approach", but rather to elicit statements of value, both implied and overt, which can be compared and contrasted. They are perhaps, therefore, more properly termed "subjects" than "participants" in these interviews. This has implications for the role of the interviewer. 
The validity of the research rests on the assumption that the metaphors used are an expression of value originating with the interviewee and not arising from the interview interaction itself; and that despite the risk that the narrative content of the interview may be to some extent a "version of the social world" constructed by the interaction of both participants (Miller \& Glassner 1997: .99), the metaphorical content of the interviewee's discourse is his or her own.

\section{Headteachers' use of metaphor}

All six headteachers, when asked directly, claimed that their school embraced the principle of parity of esteem for GNVQs. This claim was also made explicit in the policy documents of each school. Analysis of the transcripts showed that:

* There were some areas of similarity between the metaphors used by all the headteachers.

* It was possible to identify a unifying theme in each headteacher's use of metaphor.

* On the whole, the metaphors headteachers used in relation to GNVQs and GNVQ pupils were suggestive of a deficit model.

I shall now go on to take each of these points in detail.

Present in all the headteachers' discourses about GNVQ were metaphors of danger, struggle and conflict. They spoke variously of "engaging the enemy"; "trying to grapple with GNVQs"; "cracking GNVQs"; and "cracking the fear of GNVQs". There were references to "falling into a trap"; "having to defend [their] position"; "having nightmares"; and "letting a hornets' nest out onto the streets". It might be, of course, that these same images would occur if the headteachers were speaking of any other provision. The images may point beyond GNVQ to the preoccupations of headteachers striving to operate within a competitive market, rather in the same way that the sixteenth century literature on education, in its emphatic use of horticultural metaphors (Charlton, 1984), reflects a predominantly rural society. I would suggest, however, that at the very least these images 
serve to emphasise the extent to which GNVQ provision in sixth-forms is viewed not simply as a curriculum issue but as one of competition and survival (Wallace, 1999).

As well as these common images, there was evidence of a unifying theme in each headteacher's use of metaphor. It is here, I would suggest, that individual attitudes towards GNVQs emerge most clearly.

The Dietician: This headteacher used a number of metaphors which related to food and nourishment. He expressed the view that the government should "beef up" the credibility of GNVQs, which might suggest that they are insufficiently meaty or nourishing as they stand. He went on to describe key skills as "the bread and butter of it [post-16 education]". Some of the GNVQ specifications were, in his view, "difficult to digest". There may be a suggestion here that GNVQs provide a very basic and indigestible diet. His other metaphors were of dropping or falling. GNVQs risked "falling into trap"; they might "drop away" or "fall away" in a display of weakness which one might associate with undernourishment.

The Repairman: Four times in the course of the interview this headteacher described those pupils who would take the GNVQ as "damaged" ; and went on to declare that, "One of the first things we need to do is to repair that damage." Speaking of those pupils who leave the GNVQ course before completing, he said, "But we do lose some on the way that are quite badly damaged." He described GNVQ pupils as being in danger of "going to pieces" when tested; of the need to "give them a push". These metaphors, taken collectively, are suggestive of a car repair yard, where GNVQ pupils are in need of mending.

The Intensive Farmer: This headteacher used few metaphors during the interview. Those which were not to do with danger and struggle (as described at the beginning of this section) were as follows: GNVQs were described as "a batch of subjects", one of the qualifications used by society to establish "a pecking order". But if an ever-increasing number of students achieve qualifications, "the pecking order" will be impossible to establish. Meanwhile, pupils are looking for "any means they've got of unlocking that door" from school into HE.

The General: This interviewee took as his focus the school's policy of encouraging every Advanced GNVQ pupil to take an A level in addition to their GNVQ. This would 
provide "something extra in their arsenal" so that they can "command attention" when applying for HE; even though the GNVQ may be "a perfectly satisfactory bargaining chip" . At this stage his metaphors seem to suggest that $\mathrm{HE}$ is a bastion to be taken and that the GNVQ provides inadequate ammunition. His other metaphors are broadly genealogical. He refers to the additional A level as a "legitimiser"; and later as a "graft-on", suggestive of the horticultural practice of grafting high yielding growth onto sturdy but inferior root-stock.

The Stationmaster: Whether this headteacher's personal enthusiasms predisposed him to express his view of GNVQs in terms related to the railway is uncertain. However, if we take the railway to be, in his case, one of those "sustained theory-constitutive metaphors that organise our thoughts" (Taylor 1984: 7), the question becomes less significant. This headteacher repeatedly refers to post-sixteen courses as "tracks" and "parallel tracks" at that; of GNVQ provision as not yet "building up a head of steam"; of the "main track" of A level; of making sure that the "system" of post-sixteen "tracks.....runs smoothly". He describes HE as a "destination" for A level pupils and FE as a "destination" for those taking GNVQ. As well as employing the common metaphors of danger and struggle, he refers to the GNVQ as a "nettle" to be grasped; as a "relatively fringe thing" and as not "buoyant". The latter three metaphors clearly do not indicate a positive view, while the images of the railway suggest that the GNVQ is seen as one track of a dual track system with no convergence; a track where progress may be slow, even impeded, en route to a lower status destination.

The Missionary: This headteacher's discourse about GNVQs drew repeatedly upon religious imagery and biblical allusions. He described the introduction of GNVQs as "an act of faith", which had subsequently led to "much soul-searching" because many teachers feared it might "fall by the wayside". He described previous post-sixteen provision for those who performed badly at GCSE as being "of the ark"; and his role in encouraging sceptical teachers as "a little missionary exercise". In the face of general criticism about the GNVQ, the school would, he said, "try and keep the GNVQ flame going." These images, combined with those of conflict and struggle used by all headteachers, suggest a crusade, a missionary zeal. This headteacher's discourse was the only one to repeatedly stress a commitment to equality: 
"That's part of the whole school push. That's not just

GNVQ. We try to develop the idea - as every school must

be - the idea of people having importance and value....I

think that one view is that intelligent sixth-formers are

somehow better sixth-formers. And I find that obnoxious."

Even here, the GNVQ student is automatically assumed to be less intelligent.

This deficit model of the GNVQ and the GNVQ student is, I would suggest, implicit in the discourse of all six headteachers. From the Dietician's point of view the GNVQ represents an inadequate diet; for the Repair Man, GNVQ pupils are in need of patching up; the Stationmaster sees them as second class passengers on a slow track; the General sees them as lacking sufficient force. The Intensive Farmer, while utilising the GNVQ as a means of increased productivity in terms of HE entry, implies that it must accept its place in the "pecking order".

Whether or not the images upon which these headteachers draw derive from idiosyncratic preoccupations (the Stationmaster may be a train spotter, for example), is immaterial. What is important is the way in which these images are used. The Stationmaster could, for example, have referred to the GNVQ in terms of an express train, or as diesel replacing the old steam engine. The Dietician could have described it in terms of a specialised or high-energy diet or as processed food. They did not. It is not the trains or the weapons or the chickens that are significant here, but the values and contexts that are being ascribed to them. These would suggest that the headteachers' views of GNVQ were not generally consistent with their claims to accord parity of esteem to the course, the students and the qualification.

\section{Teachers' use of metaphor}

My second question was concerned with whether there was some thematic congruence between a headteacher's predominating metaphor for GNVQ and that used by his staff. This question broadly explores the work of Beare (1987); Beare et al (1989); and Goens (1996), described in a previous section. In other words, did the Stationmaster's staff 
describe the GNVQ in terms of a slow train, or the Dietician's in terms of a poor meal, and so on? There was no consistent or conclusive evidence of this. There were, however, examples of teachers using metaphors which were consistent in tone with those used by their headteacher. One of the teachers at the Missionary's school, for example, spoke of GNVQ pupils in terms that might be described as visionary:

"The dream, I think, is that they are held in higher esteem - that's the dream.....And so the dream is that they're going to point the way. And other sixthformers are going to be saying, "I want to learn how to do that," you know. And that - that's the dream."

The metaphor of the dream does not occur in his headteacher's discourse; but in the sense that this dream suggests a proselytising fervour, an echo of Martin Luther King perhaps, one could argue that there is some consistency of vision here.

In another sense, however, there was an obvious congruence in teachers' and headteachers' choice of images about GNVQs, in that they were all equally at odds with the overt claims being made about parity of esteem. This is illustrated by the following examples of teachers' metaphor.

The GNVQ as unwanted child. Here the teacher describes GNVQ provision in the school as "embryonic"; establishes that he became involved with it willingly by explaining that "it wasn't a shotgun wedding scenario"; and expresses his feelings of unpreparedness by claiming that "it [the GNVQ teaching] sort of fell on to my lap after it had been born." The GNVQ as a burden. This teacher complained that the GNVQ was "a large block of work for them [the pupils] to do", and that they "only gradually pick it up", after which they "tend to struggle with it." Their coursework "piles on and piles on", so that many pupils "decide to drop it."

The GNVQ as a difficult race. This teacher describes the GNVQ course as a series of "hurdles". When pupils complete their first assignment they have "jumped that hurdle", and if they pass a unit test "they've gone through (sic) that hurdle". For most GNVQ pupils 
the course is "an uphill struggle", although the integration of key skills into A level courses may "level things up."

The GNVQ teacher as the guardian angel or the teacher from hell. This teacher (who was not, incidentally, from the Missionary's school) was concerned primarily with the fact that, in his view, GNVQ pupils were not able to work independently but needed constant help from the teacher. He expressed this as their need for a teacher who was "a little guardian angel sat on their shoulder, advising them about which key skills they particularly need to do." However, because he persisted in encouraging pupils to be independent, he feared that they saw him as "the teacher from hell."

The GNVQ as excrement . This teacher described her GNVQ pupils as "thick as pig shit", and claimed that her own GNVQ-related activities required her to be "buzzing around like a blue-backsided fly." The fact that these are similes rather than metaphors does not detract from the point being made.

These were not the only examples of figurative language used by each teacher; but they were ones which could be identified as repetitive or suggestive of a theme in that teacher's discourse.

Conclusion. In the first section of this paper I suggested that analysis of metaphor may provide insight into a speaker's otherwise unexpressed values and beliefs; in other words, that metaphor may make unspoken assumptions explicit. I went on to describe some ways in which this has been applied in educational research and research into leadership and organisations generally. I then went on to show how I had used metaphor analysis to address two questions:

(i) Are claims that GNVQs are accorded parity of esteem borne out by the metaphors used in relation to GNVQs by GNVQ teachers and their headteachers in six secondary schools? (ii) Is there any evidence that there is a thematic consistency in the metaphors used to describe GNVQ provision in each school?

Let us now consider some of the conclusions that might usefully be drawn from this analysis. 
Certainly, the metaphors which headteachers employ when talking about the GNVQ and GNVQ pupils suggest a deficit model. This may have implications for the initial selection and recruitment of these pupils on to the GNVQ courses. If recruitment is aimed at the less able pupils, their subsequent poor performance may serve simply to reinforce the unspoken prejudices which teachers and headteachers hold about such courses. All six headteachers draw upon metaphors of conflict and struggle when speaking of GNVQ provision, which may indicate difficulties perceived in introducing it to their post-sixteen curriculum, or preoccupations with competition and survival in the market for post-sixteen education. Indeed, there is some evidence here to suggest that headteachers may view the introduction of the GNVQ largely as a recruitment tactic, aimed at those less able pupils who had not traditionally stayed on at school at age sixteen. These are the students who must now be competed for in order to maintain or raise school rolls in a market where schools are in competition with each other and with local colleges.

The nature of the metaphors used by teachers and headteachers would seem to contradict the claim that GNVQs are esteemed equally with A levels, since they draw upon negative rather than positive analogies. In other words, the rhetoric of the government white papers is not reflected by what is happening in these schools, where the principle of parity is often ostensibly supported but unconsciously contradicted in the same interview. There are several possible explanations for this, all of them interconnected. It may be that a pragmatic, market-led decision to introduce the course is being given educational justification by recourse to the rhetoric, despite deep-seated assumptions about its "real" status. On the other hand, it is possible that the persisting confusion about the currency value or equivalence of the qualification, combined with the pervasive rhetoric about parity, creates a dissonance which we see reflected in the views of teachers and headteachers. Another explanation - and perhaps the most interesting one - is that these contradictions reflect a dilemma at the heart of an education policy: how to establish parity for vocational qualifications while clearly valuing academic qualifications more highly.

The only clear sense in which teachers' and headteachers' metaphors may be said to consistently match within the individual schools is in their unequivocal reflection of the relatively low value attached to the GNVQ and GNVQ pupils. The exception here is at the school where the Missionary is headteacher. Here, although GNVQ pupils are described as 
less intelligent, the metaphors used in relation to them would suggest that they are not valued any the less for that.

The findings do not seem to reflect those of Beare (1987) and David and Graham (1997) discussed earlier in this paper in that the specific images employed in these teachers' metaphors do not echo those of their headteachers. Neither is it claimed here that broad generalisations about covert and overt attitudes towards the GNVQ can be drawn from these six schools. One might be led to question, however, whether teachers' and headteachers' expressed views on GNVQs and GNVQ students should always be taken at face value. What does emerge also, I would suggest, is that metaphor analysis can provide a useful tool for exploring and testing the explicitly expressed value judgements of research participants.

Finally, it is interesting to reflect upon what the consequences might be if these headteachers consciously chose to use more positive images of GNVQ in their professional discourse; for, as Hudson (1984: 76) points out,

"Rather than living unwittingly, unreflectively, in the grip of certain metaphors, we could learn to pick and choose."

According to Beare (1987), the adoption by principals or headteachers of positive metaphors to describe the work of their institution can bring about a cultural change within the school. As for parity of esteem for GNVQs, this inquiry would seem to bear out Vico's claim that the language and the imagery that we use constitute a more reliable source of data about the attitude of our times than any conscious record (Berlin, 1976: 88); and that if such claims about parity are to go beyond mere rhetoric, then the words we use should be more carefully chosen. 


\section{References}

Beare, H. (1987). Metaphors about schools: the principal as cultural leader. In W. Simpkins , A. Ross Thomas, \& E. Barrington Thomas (Eds.) Principal and change: the Australian Experience (pp. 275-296). Armidale: University of New England.

Beare, H; Caldwell,J. \& Millikan,R. (1989). Creating an excellent school: some new management techniques. London and New York: Routledge.

Beavis, A. \& Thomas, A. (1996). Metaphors as storehouses of expectation. Educational Management and Administration , 24 (1), 93 -106.

Berlin, I. (1976). Vico and Herder: two studies in the history of ideas. London: The Hogarth Press.

Black, M. (1962). Models and metaphors. New York: Cornell University Press.

Black, M. (1979), More about metaphor. In A Ortony (Ed.), Metaphor and thought. (pp. 19 -41). Cambridge: Cambridge University Press.

Bliss, J; Monk, M. \& Ogborn, J. (1983). Qualitative data analysis for educational research. London: Croom Helm.

Bowring-Carr, C. (1993). How shall we know quality in teaching and learning? Some problems associated with classroom observation. The Curriculum Journal , 4 (3), 319 -326.

Buchan, J. (1936). The Island of Sheep. London: Thos Nelson and Sons Ltd.

Charlton, K. (1984). The paradox of metaphor: a sixteenth century casestudy. In W. Taylor (Ed.), Metaphors of education (pp. 54-67). London: Heinemann. 
Cohen, L. \&Margalit, A. (1972). The role of inductive reasoning in the interpretation of a metaphor. In D. Davidson and G. Harmon (Eds.), Semantics of Natural Language (pp. 69 93). Dordrecht: D. Reidel.

David, C. \& Graham, M. (1997). Conflicting values: team management portrayed in epic metaphors. Journal of Business and Technical Communication, 11 (1), $24-48$.

de Botton, A. (1997). How Proust can change your life. London: Picador.

Eco, U. (1990). Overinterpreting texts. In S. Collini (Ed.) (1992) Interpretation and Overinterpretation (pp. 45 - 67). Cambridge: Cambridge University Press.

Freire, P. (1972). Pedagogy of the Oppressed. Harmondsworth: Pelican.

Goens, G. (1996). Does your school have a soul? Principal , 76 (1), 54.

Goodson, I. \& Walker, (1988). Putting life into educational research. In R. Sherman, \& R. Webb (Eds.), Qualitative research in education: focus and methods (pp. 110-122). London: The Falmer Press.

Hill, F. (1995). Why the conceptualization of students as consumers need not imply limited educational vision. Journal of General Education , 44 (4), 222 - 226.

Holstein, J. and Gubrium, J. (1997). Active interviewing. In D. Silverman Ed.) Qualitative research: theory, method and practice (pp. 113 -129). London: Sage.

Hudson, L. (1984). The role of metaphor in psychological research. In W. Taylor (Ed.), Metaphors of education (pp.68 -78). London: Heinemann. 
Inbar, D. (1991). A metaphorical insight into educational planning. Journal of Educational Administration, 29 (3), 23 -37.

Lakoff, G. \& Johnson, M. (1980). Metaphors we live by. Chicago and London: University of Chicago Press.

Lakoff, G. \& Turner, M. (1989). More than cool reason: a field guide to poetic metaphor. Chicago and London: The University of Chicago Press.

Miller, J. \& Glassner, B. (1997). The 'inside' and the 'outside': finding realities in interviews, in D. Silverman (Ed.), Qualitative research: theory, method and practice (pp.99 -112). London: Sage.

Orwell, G. (1962). Inside the whale and other essays. Harmondsworth: Penguin.

Powney, J. \& Watts, M. (1987). Interviewing in educational research. London: Routledge \& Kegan Paul.

Samuels, A. (1985). Jung and the post-Jungians . London, Boston and Henley: Routledge \& Kegan Paul.

Spence, L. (1995). Metaphors, dead or alive: a reply to "transcending the limited educational vision implied by the consumer metaphor". Journal of General Education , 4 (4), 227 - 233.

Taylor, W. (1984). Metaphors of Educational Discourse. In W. Taylor (Ed.), Metaphors of education (pp. 4 -20). London: Heinemann.

Vico, G. (1961). The new science of Giambattista Vico. New York: Anchor Books, Doubleday \& Co. Inc. 
Wallace, S. (1999). Less equal than others: a study of GNVQ provision in six secondary schools. Research in Post-compulsory Education, 3 (3), 345 - 356.

Way, E. (1994). Knowledge representation and metaphor. Oxford: Intellect Books. 
